\title{
Pembangunan Aplikasi Permainan Edukasi "Teka-Teki Muslim" untuk Remaja Masjid Prisma Al-Mustaqim menggunakan Metode Game Development Life Cycle
}

\author{
Nazifa Putri Hutami ${ }^{1}$, Reynaldi Prathama ${ }^{2}$, Sitta Fadillah ${ }^{3}$ \\ Universitas Paramadina, Jl. Gatot Subroto Kav. 97, Mampang, Jakarta, Indonesia
}

\begin{tabular}{|c|c|}
\hline Info Artikel & ABSTRAK \\
\hline & Remaja yang gagal identik dengan perilaku menyimpang yang \\
\hline Riwayat Artikel & disebut kenakalan remaja. Salah satu solusi yang dapat \\
\hline Diterima: $11-12-2020$ & dilakukan dalam mengatasi hal kenakalan remaja adalah dengan \\
\hline Direvisi: $21-12-2020$ & mengajarkan pemahaman ajaran agama yang selalu membawa \\
\hline Disetujui: $30-12-2020$ & para umatnya kejalan yang benar. Seperti halnya yang dilakukan \\
\hline & oleh PRISMA (Pemuda Remaja Islam) Masjid Al-Mustaqim. \\
\hline Kata Kunci & $\begin{array}{l}\text { Dalam rangka mengembalikan pemahaman ajaran islam agar } \\
\text { menjadi pribadi yang akhlakul karimah. PRISMA Al-Mustagim }\end{array}$ \\
\hline Remaja; & mengadakan program kerja yang dimana setiap minggu \\
\hline Organisasi Remaja Masjid; & diadakannya pembelajaran ajaran agama islam. Akan tetapi \\
\hline Game Edukasi; & terdapat berbagai kendala dalam menyampaikan pemahaman \\
\hline GDLC; & $\begin{array}{l}\text { ajaran islam. Salah satu kendalanya adalah para anggota cepat } \\
\text { bosan. Namun terdapat cara yang dapat dilakukan untuk } \\
\text { mengatasi hal tersebut adalah dengan mengimbangi ilmu agama }\end{array}$ \\
\hline$\triangle$ Corresponding Author & dengan kemajuan teknologi yaitu dengan membangun \\
\hline Sitta Fadillah, & permainan edukasi. Game edukasi "TTM" dibuat untuk \\
\hline Tel. +62 89505275208 & memberikan informasi seputar materi pada kitab khilyatul wal \\
\hline sittafadillah66@gmail.com & banin pada bab puasa dan sedekah. Proses pembuatan game \\
\hline & $\begin{array}{l}\text { "TTM" menggunakan metode GDLC (Game Development Life } \\
\text { Cycle) yang memiliki tahapan yaitu Initiation, Pre-Production, } \\
\text { Production. Testing. Beta dan Release. }\end{array}$ \\
\hline
\end{tabular}

\section{PENDAHULUAN}

Di era globalisasi ini masyarakat Indonesia sedang mengalami perkembangan yang sangat pesat. Kemajuan teknologi menyebabkan perubahan dalam kehidupan manusia dan segala budayanya. Era ini berpotensi memiliki dampak pada proses nilai- nilai yang ada di masyarakat, khususnya kaum remaja. Istilah remaja seringkali dipandang sebagai masa paling rentan serta dikenal dengan pemberontakan dalam proses kehidupan. Remaja yang gagal identik dengan perilaku menyimpang yang disebut kenakalan remaja. Terlebih remaja awal berusia 12-15 tahun dikarenakan dalam tahap itu remaja memiliki ciri ketidakstabilan hingga masa di mana remaja berhasil membentuk teori tentang dirinya, masih dalam masa pencarian identitas sehingga pada masa itu dibutuhkannya asupan-asupan ilmu yang bermanfaat [1]. Salah satu solusi yang dapat dilakukan dalam mengatasi hal kenakalan remaja adalah dengan mengajarkan pemahaman ajaran agama yang selalu membawa para umatnya kejalan yang benar [2]. Akan tetapi kondisi pendidikan Islam pada saat ini berada dalam kondisi dimana satu sisi umat Islam bangga karena dulunya mempunyai para ilmuwan-ilmuwan besar dan mempunyai turut andil yang besar bagi pembangunan peradaban dan ilmu pengetahuan dunia, namun di sisi lain dihadapi dengan sebuah kenyataan, bahwa pendidikan Islam tidak berdaya dihadapkan kepada realitas masyarakat industri dan teknologi modern [3]. 
Dari keterangan diatas dapat dikatakan bahwa pendidikan agama sekarang dapat menjadi sorotan masyarakat. Memang tidak adil jika menimpakan tanggung jawab munculnya kesenjangan antara harapan dan kenyataan itu kepada pendidikan agama di sekolah. Salah satu contoh faktornya adalah faktor lingkungan [4]. Dalam faktor lingkungan, biasanya terdapat organisasi remaja masjid. Organisasi remaja masjid adalah suatu perkumpulan remaja muslim yang menggunakan masjid sebagai pusat aktivitasnya. Organisasi remaja masjid menjadi salah satu jalan alternatif dalam pembinaan remaja yang terbaik [5]. Seperti halnya yang dilakukan oleh PRISMA (Pemuda Remaja Islam) Masjid Al-Mustaqim. Dalam rangka mengembalikan pemahaman ajaran islam serta pendidikan akhlakul karimah bagi remaja masjid Al-Mustaqim. Sebagaimana mestinya, PRISMA memiliki program kerja yang dimana setiap seminggu sekali diadakan pembelajaran materi berdasarkan khitab khilyatul wal banin yang memang diperuntukkan untuk anak-anak remaja awal. Metode pembelajaran yang dipakai menggunakan metode pembelajaran mendengar. Akan tetapi metode tersebut dianggap sewajarnya sehingga membuat para remaja mudah bosan.

Menurut [6] dalam jurnalnya yang berjudul "Pendidikan Moral Kids Zaman Now Dalam Perspekti Islam" mengatakan bahwa cara yang dapat dilakukan untuk mengatasi hal tersebut adalah dengan mengimbangi ilmu agama dengan kemajuan teknologi. Hal ini akan membuat remaja menjadi remaja yang tidak ketinggalan zaman (sains dan teknologi) juga menjadi anak yang berakhlakul karimah. Dikarenakan itu, para remaja masjid membutuhkan sebuah sistem atau media pembelajaran agar menambah semangat belajar dan menghilangkan rasa bosan remaja. Permainan edukasi bisa menjadi jalan alternatif sebagai media pembelajaran untuk siswa dalam proses belajar. Dengan bantuan media berbasis komputer akan memudahkan pengajar dalam menyampaikan materi kepada pelajar [7].

Dalam penelitian ini penulis akan membuat sebuah aplikasi permainan edukasi sebagai media pembelajaran baru bagi para remaja. Jenis permain yang akan dibangun berupa crossword puzzle games menggunakan metode pengembangan permainan yaitu game development life cycle. Dengan adanya aplikasi permainan edukasi ini diharapkan para remaja dapat meningkatkan pemahaman belajar mereka terhadap ajaran agama islam sehingga dapat diterapkan dalam kehidupan sehari hari.

\section{METODE}

Subjek dalam penelitian ini adalah remaja masjid PRISMA Al-mustaqim di kecamatan Mampang Prapatan. Teknik pengumpulan data dilakukan dengan cara kualitatif yaitu melalui wawancara dan studi pustaka kepada subjek penelitian. Kemudian Dalam pembangunan aplikasi permainan edukasi "teka-teki muslim" ini, penulis menggunakan metode pengembangan yang dikenal dengan metode Game Development Life Cycle (GDLC). GDLC adalah suatu proses pengembangan sebuah game yang menerapkan pendekatan iteratif yang terdiri dari 6 fase pengembangan, dimulai dari fase inisialisasi/pembuatan konsep, preproduction, production, testing dan realease [8]. Adapun 6 tahapan yang digunakan dalam metode pengembangan GDLC, yaitu:

\section{Initiation}

Pada tahap ini berupa pembuatan konsep kasar dari game. Penulis akan mempersiapkan kebutuhan game yang akan digunakan. Mulai dari menjelaskan jenis permainan, gameplay, game art, target user dari game yang dibuat.

2. Pre-Production

Pada tahap ini penulis akan mendeksripsikan perencanaan berupa storyboard.

3. Production

Pada tahap ini penulis mengerjakan bagian inti dari pembuatan game. Pengerjaan dimulai dari mengumpulkan asset yang dibutuhkan hingga ke pengkodean dan pengembangan game.

4. Testing 
Pada tahap ini penulis akan menguji aspek fungsi dan konten dalam game. Pengujian dilakukan dalam penggunaan fitur-fitur dalam game dan tingkat kesulitan dalam game. Pengujian ini dilakukan dengan menggunakan metode black box testing berupa tabel yang akan menerangkan apakah masing-masing fitur pada aplikasi sudah merespon dengan baik.

5. Beta

Pada tahap ini game yang dibuat akan diberikan kepada penguji pihak eksternal. Pengujian Beta dilakukan secara langsung ke end user atau pengguna akhir. Pengujian ini untuk mendeteksi keluhan dari penguji terhadap game edukasi "TTM". Hasil dari pengujian ini dapat menyebabkan penulis mengulangi siklus lagi.

6. Release

Tahap ini merupakan tahap terakhir, dimana game telah selesai dibangun dan lulus tahap beta maka siap dirilis dan disampaikan kepada pengguna.

\section{HASIL DAN PEMBAHASAN}

Adapun yang menjadi hasil dari penelitian ini adalah pembangunan sebuah game edukasi sebagai metode pembejaran baru yang lebih interaktif bagi remaja, dimana dalam pembuatan permainan edukasi ini digunakan metode Game Development Life Cycle seperti yang dijelaskan pada bagian sebelumnya.

1. Initiation

Tahapan ini merupakan tahapan dimana dilakukan pembuatan desain game, desain game berfokus untuk menjelaskan jenis permainan, target pemain, dan gameplay.

- Jenis Permainan

Jenis permainan yang akan dibangun berupa Crosswods Puzzle Games karena merupakan permainan yang menyajikan teka-teki silang.

- Target Permainan

Target dalam permainan ini adalah untuk remaja masjid PRISMA Al-Mustaqim khususnya remaja berusia 12-15 tahun.

- Gameplay

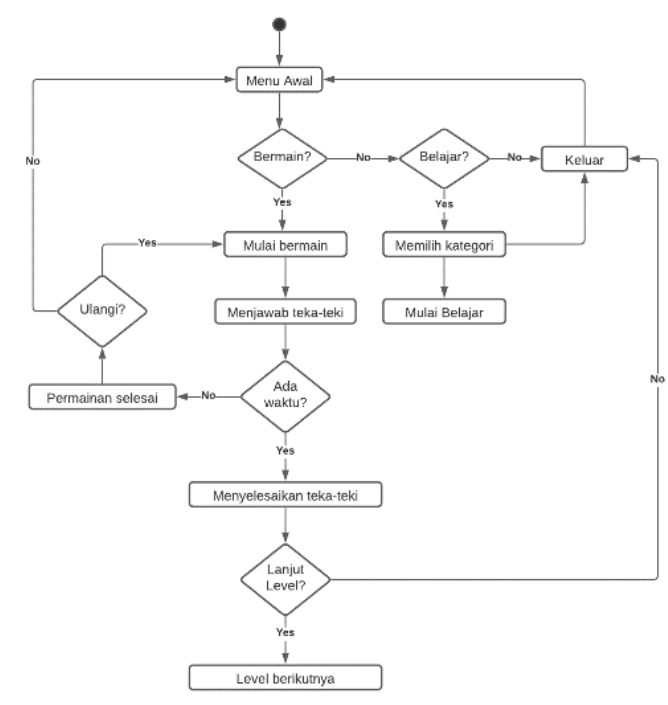

Gambar 1. Gameflow Permainan Edukasi "TTM"

- Game Art

Game art ini menjelaskan elemen-elemen visual yang membuat sebuah video game menjadi bergaya dan modern. Elemen tersebut antara lain adalah video game, seperti background, logo, tombol, huruf, dan audio. Pada latar belakang dan aset-aset yang digunakan dalam aplikasi permainan edukasi ini diambil dari website yang menyediakan gambar yang berupa vector yaitu freepik.com.

\section{Pre-Production}


Pada tahapan ini penulis akan mendeskripsikan perencanaan berupa storyboard yang akan mewakili gambaran dari aplikasi permainan ini.

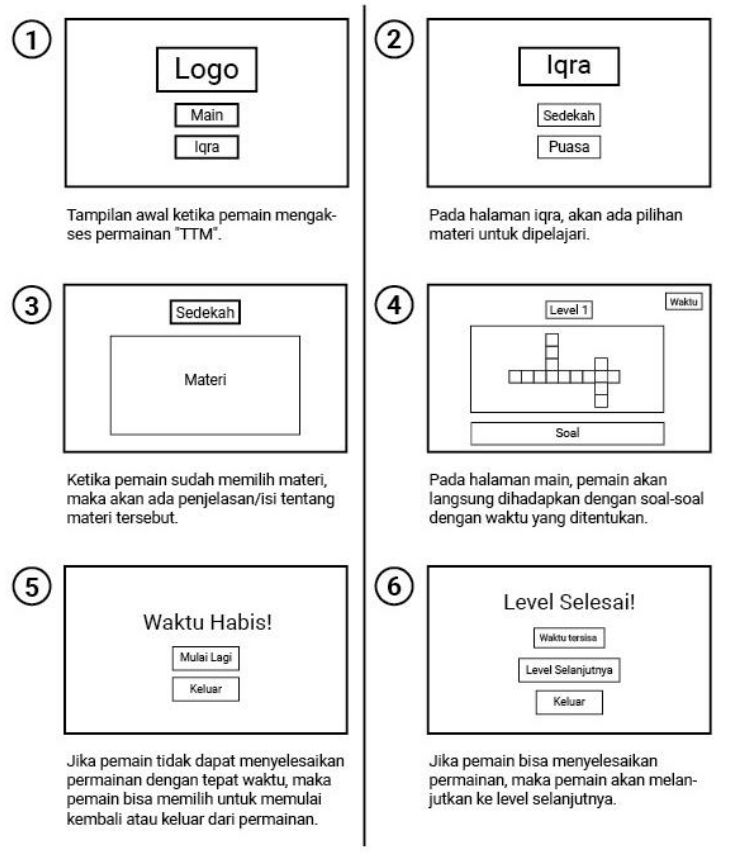

Gambar 2. Storyboard Permainan Edukasi "TTM"

Pada penjelasan 1 adalah saat pemain membuka aplikasi permainan pertama kali dan muncul tampilan halaman awal yang terdiri dari tombol "Main" untuk memulai bermain, "Iqra" untuk memulai belajar materi. Pada penjelasan 2, pemain memilih menu "Iqra" dan akan muncul pilihan kategori materi untuk dibaca dan dipelajari Pada gambar 3, tampilan isi dari materi yang dipilih pemain yang terdiri atas penjelasan atau teori. Pada gambar 4, ketika memilih menu "Main" akan dihadapkan langsung bermain yaitu teka-teki silang dengan jawaban mengisi kotak-kotak kosong menurun dan mendatar berdasarkan soal-soal yang diberikan. Pada penjelasan 5, tampilan halaman ketika pemain tidak dapat menyelesaikan permainan dengan tepat waktu. Pemain akan dapat memilih untuk mengulang level atau keluar. Pada penjelasan 6, tampilan halaman ketika pemain dapat menyelesaikan permainan dengan tepat waktu. Halaman permainan akan menampilkan waktu yang tersisa ketika bermain. Dan pemain akan dihadapkan untuk melanjutkan permainan ke level beikutnya atau memilih keluar. Pada halaman ini terdapat soal-soal telah dipilih yang harus dijawab oleh pemain dengan mengetik jawaban di kotak putih kosong. Ketika menjawab soal dengan jawaban yang salah, maka akan muncul popup "SALAH".

\section{Production}

Pada tahapan Production ini, penulis melakukan implementasi dari proses perancangan yang telah dibuat sebelumnya ke dalam bahasa pemrograman dengan proses pengkodean. Permainan edukasi "TTM" ini dibuat dengan bahasa pemrograman HTML, Javascript, Bootstrap, CSS Framework dan jQuery. Dalam tahapan ini penulis akan menjelaskan persiapan tools yang digunakan dalam pembuatan permainan edukasi "TTM", implementasi antarmuka dan implementasi aplikasi.

\section{- Persiapan Peralatan Pendukung}

Penulis menggunakan perangkat lunak dalam pembangunan permainan edukasi "TTM" diantaranya adalah :

1. Sublime Text 3, sebagai code editor

2. Web browser Google Chrome yang digunakan untuk membuka aplikasi.

\section{- Implementasi Antarmuka}

Tahapan selanjutnya adalah penulis melakukan implementasi permainan edukasi "TTM" melalui tahap pemrograman. Berikut ini adalah antarmuka dari permainan edukasi "TTM". 


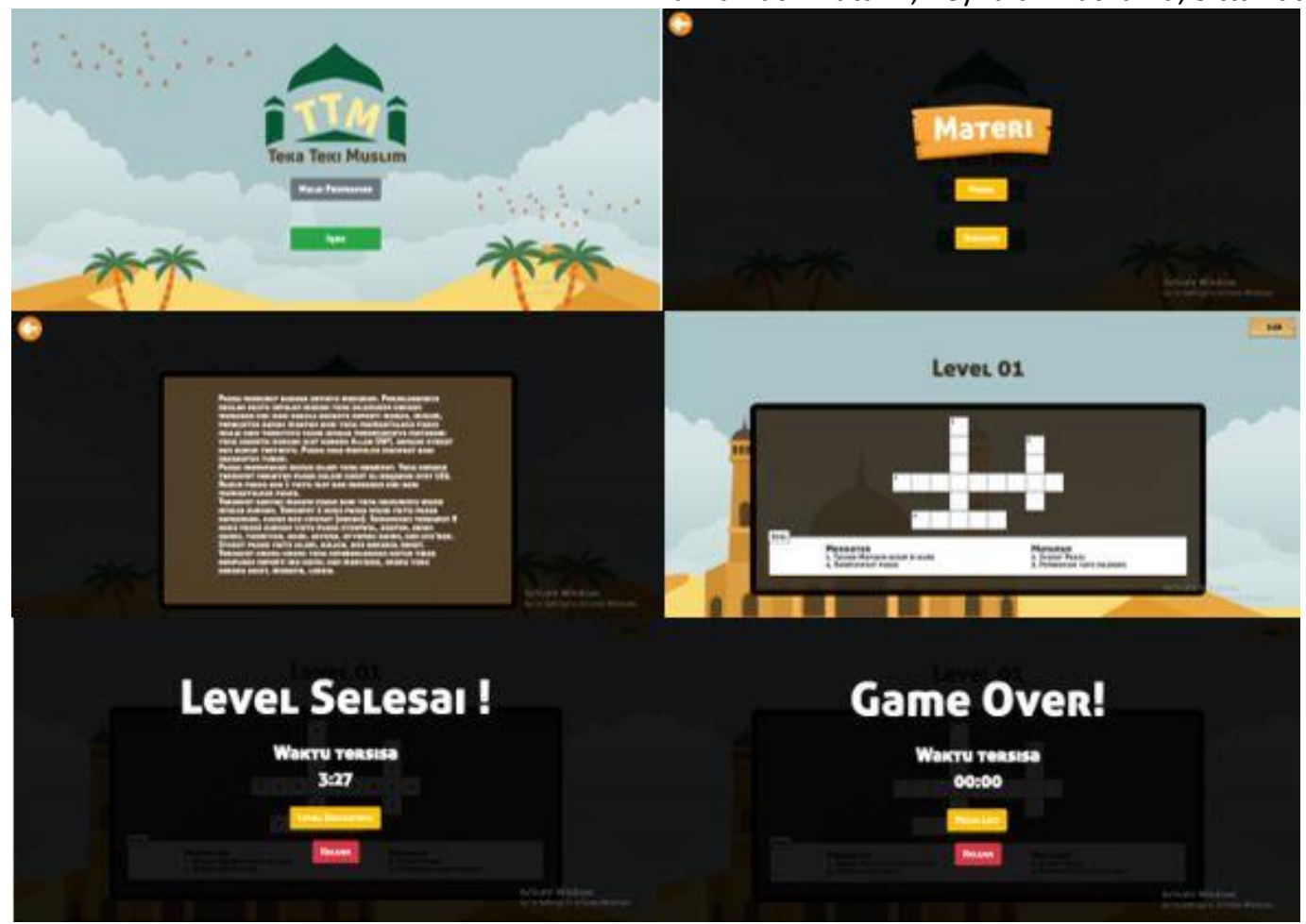

Gambar 3. Implementasi antarmuka Permainan Edukasi "TTM"

\section{- Implementasi Aplikasi}

Tahapan selanjutnya adalah mengimplementasikan antarmuka yang telah dibuat dalam bentuk aplikasi berbasis web. Seperti yang sudah dijelaskan sebelumnya, aplikasi permainan edukasi ini dibuat dengan bahasa pemrograman HTML, CSS dengan Framework Bootstrap, jQuery dan Javascript

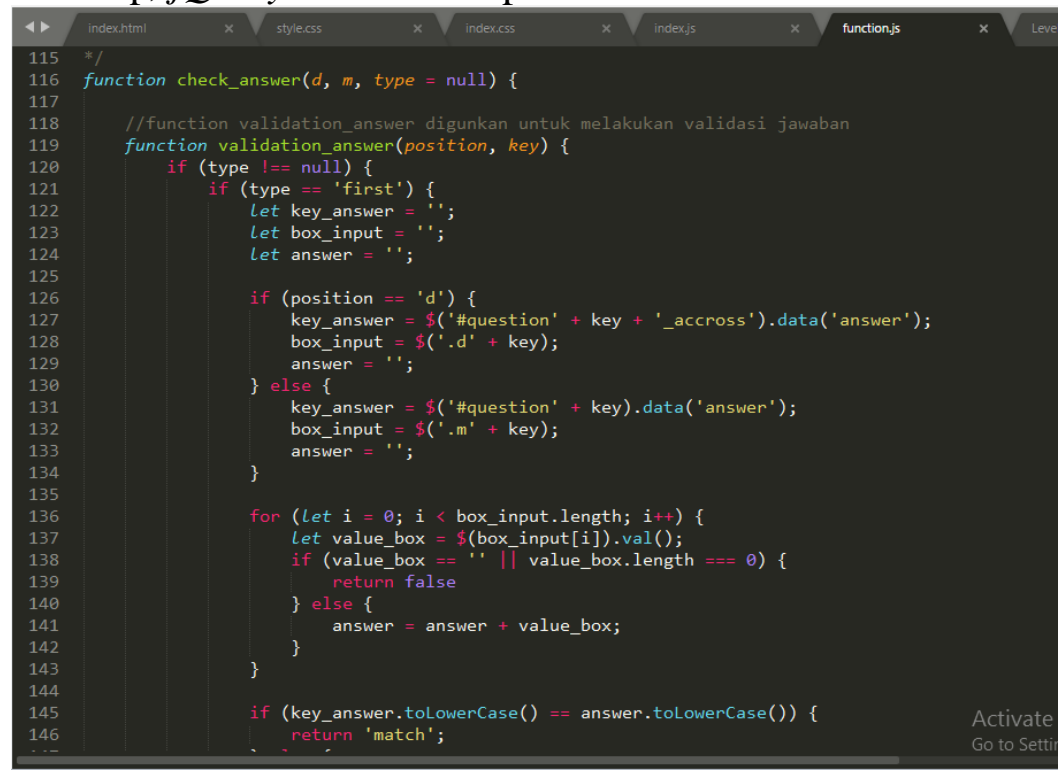

Gambar 4. Potongan Kode Program Pada File Function.Js Untuk Melakukan Validasi Jawaban

\section{Testing}

Pada fase ini penulis akan melakukan pengujian pada aplikasi permainan edukasi "TTM" ini menggunakan metode black box testing dimana dengan black box testing ini untuk memastikan bahwa permainan edukasi yang telah dibangun sesuai dengan kebutuhan dan semua fungsi yang ada berjalan dengan baik. Tahapan pengujian ini berfokus pada dua aspek yaitu konten dan fungsional. Tahap pengujian testing ini dilakukan kepada Ketua Remaja Masjid PRISMA Al-Mustaqim. 
Tabel 1. Hasil black box testing kepada Ketua Remaja Masjid

\begin{tabular}{cllcc}
\hline \multirow{2}{*}{ No } & \multirow{2}{*}{ Fungsi } & Skenario Pengujian & \multicolumn{2}{c}{ Hasil Pengujian } \\
\cline { 3 - 4 } & & Konten & Fungsi \\
\hline 1. & Halaman awal & Ketua mengakses aplikasi permainan edukasi “TTM” & Ok & Sukses \\
2. & Halaman iqro & Ketua klik tombol iqro pada halaman awal & Ok & Sukses \\
3. & Halaman memilih & Ketuaklik tombol memilih materi yang ingin dipelajari & Ok & Sukses \\
4. & Halaman menu materi & $\begin{array}{l}\text { Ketua klik tombol ikon lanjut pada materi yang } \\
\text { ditampilkan sistem }\end{array}$ & Ok & Sukses \\
5. & Halaman main & Ketua klik tombol main pada halaman awal aplikasi & Ok & Sukses \\
6. & Memainkan permainan & $\begin{array}{l}\text { Ketua memainkan dengan cara klik kolom jawaban } \\
\text { lalu mengisi jawaban dengan waktu yang ditentukan }\end{array}$ & Ok & Sukses \\
\hline
\end{tabular}

Berdasarkan hasil uji diatas terlihat baik dari sisi fungsionalitas dan konten permainan edukasi "TTM" sudah berjalan dengan sangat baik dan sesuai dengan harapan dari penulis. Tetapi terdapat masukan atau saran dari ketua masjid berupa soal jawaban benar. Sebelum diperbaiki, soal yang sudah dijawab dengan benar tidak memiliki pemberitahuan baik dari pop-up ataupun sound. Menurut ketua remaja masjid, itu akan membuat pemain tidak fokus dalam membaca soal dan mengecek jawaban. Selain itu membuat bingung membaca mana soal yang sudah dijawab dan tidak sehingga pemain akan membaca secara berkali-kali dalam satu level dan akan memakan waktu yang sudah ditentukan. Setelah diperbaiki soal yang sudah dijawab dengan benar oleh pemaian, sistem akan secara otomatis mencoret soal yang sudah diisi dengan benar dan jika jawaban salah maka akan keluar sound.

5. Beta

Pengujian Beta dilakukan dengan cara menguji permainan Edukasi "TTM" secara langsung ke end user atau pengguna akhir. Responden adalah salah satu anggota remaja masjid yang berusia 13 tahun. Responden akan memainkan aplikasi permainan edukasi "TTM" terlebih dahulu. Setelah memainkan permainan penulis melakukan evaluasi terhadap pengunaan aplikasi permainan edukasi "TTM".

Tabel 2. Hasil Black Box Testing Kepada End User

\begin{tabular}{cllcc}
\hline \multirow{2}{*}{ No } & Fungsi & Skenario Pengujian & \multicolumn{2}{c}{ Hasil Pengujian } \\
\cline { 3 - 5 } & & Kotua mengakses aplikasi permainan edukasi "TTM" & Fungsi \\
\hline 1. & Halaman awal & Ok & Sukses \\
2. & Halaman iqro & Ketua klik tombol iqro pada halaman awal & Ok & Sukses \\
3. & Halaman memilih & Ketuaklik tombol memilih materi yang ingin dipelajari & Ok & Sukses \\
4. & Halaman menu materi & $\begin{array}{l}\text { Ketua klik tombol ikon lanjut pada materi yang } \\
\text { ditampilkan sistem }\end{array}$ & Ok & Sukses \\
5. & Halaman main & $\begin{array}{l}\text { Ketua klik tombol main pada halaman awal aplikasi } \\
\text { 6. }\end{array}$ & Ok & Sukses \\
& Memainkan permainan & $\begin{array}{l}\text { Ketua memainkan dengan cara klik kolom jawaban } \\
\text { lalu mengisi jawaban dengan waktu yang ditentukan }\end{array}$ & Ok & Sukses
\end{tabular}

Berdasarkan hasil uji diatas terlihat baik juga dari sisi fungsionalitas dan konten permainan edukasi "TTM" sudah berjalan dengan sangat baik dan sesuai dengan harapan dari penulis. Akan tetapi terdapat keluhan dalam waktu permainan. Yang dimana sebelum diperbaiki, waktu permainan dalam permainan ini memiliki konsep dimana dalam satu level memiliki beberapa soal dan satu soal memiliki waktu 30 detik. Sehingga jika dalam satu level memiliki 5 soal maka waktu yang ditentukan adalah 150 detik. Bagi responden yang terpilih untuk melakukan beta, waktu yang digunakan tersebut terlalu cepat jika dimainkan untuk responden. Dikarenakan mereka masih dalam tahap pembelajaran baik disekolah maupun lingkungan. Setelah hasil diskusi dengan ketua remaja masjid prisma dan responden, akhirnya disetujui waktu diubah menjadi satu soal 1 menit.

\section{Release}


Setelah tahapan evaluasi beta selesai, tahapan selanjutnya pada metode GDLC adalah perilisan permainan edukasi "TTM" kepada remaja PRISMA Al-Mustaqim usia 12-15 tahun dan siap untuk dimainkan.

\section{SIMPULAN DAN SARAN}

Dalam pembangunan aplikasi permainan edukasi ini di harapkan dapat memberikan pendidikan, hiburan, dengan tampilan yang menarik, efisien, efektif, dan juga menghibur, serta sebagai akhir dari laporan ini, penulis dapat menarik kesimpulan sebagai berikut bahwa Permainan edukasi "TTM" dibuat untuk memberikan informasi seputar materi pada kitab khilyatul wal banin dengan bab puasa dan sedekah. Proses pembuatan permainan "TTM" menggunakan metode GDLC (Game Development Life Cycle) yang memiliki tahapan yaitu Initiation, Pre-Production, Production, Testing, Beta, dan Release. Permainan edukasi bernama "TTM" ini dibuat dalam bentuk web dan diakses secara offline. Pada permainan ini remaja masjid akan dihadapi dengan mengisi jawaban pada kolom kotak dengan huruf-huruf sesuai dengan pertanyaan. Kemudian remaja masjid memainkannya dengan cara klik kolom kotak dan membaca pertanyaan dan menulis jawaban yang sesuai dengan soal yang sudah diberikan.

Kemudian saran terhadap penelitian ini agar penelitian ini selanjutnya dapat menjadi Sarana penelitian dan pengembangan lebih lanjut, hasil penelitian ini dapat digunakan dalam bidang pengembangan media pembelajaran. Permainan dapat dikembangkan dengan membuat aplikasi yang diakses secara online, Hal ini agar mempermudah pengguna di zaman era saat ini yang dalam sehari-harinya menggunakan internet. Kemudian Permainan dapat dikembangkan dengan membuat aplikasi berbasis android atau iOS. Hal ini agar mempermudah pengguna dalam memainkan permainan ini di perangkat apa saja.

\section{DAFTAR PUSTAKA}

[1] M. Wedan, "Perkembangan Psikologi, Karakteristik Anak Usia Sekolah Menengah (SMP)," Silabus, 2016.

[2] M. Huda, "JUVENILE DELIQUENCY IN ISLAMIC EDUCATION PERSPECTIVE (KENAKALAN REMAJA DALAM PERSPEKTIF PENDIDIKAN ISLAM)," $A l$ Afkar; J. Islam. Stud., vol. 2, no. 1, pp. 176-183, 2019.

[3] K. Santoso, "Problematika Pendidikan Islam Masa Kini, Kajian Fundasional dan Operasional," Duta.co, 2020.

[4] A. Karnesyia, "3 Faktor Penting Pengaruhi Pembentukan Karakter Anak," Hai Bunda, May-2019.

[5] A. Diani, "PERANAN ORGANISASI REMAJA ISLAM MASJID JAMI' BAITURROHIM DALAM MEMBINA MORAL REMAJA DI DESA KUALA SEKAMPUNG KECAMATAN SERAGI KABUPATEN LAMPUNG SELATAN," Raden Intan, 2019.

[6] A. A. Syukron, "PENDIDIKAN MORAL KIDS ZAMAN NOW DALAM PERSPEKTIF ISLAM,” J-PAI J. Pendidik. Agama Islam, vol. 4, no. 2, Jun. 2018.

[7] S. Munawar, "Perkembangan Teknologi dalam Pendidikan di Sekolah," 2015.

[8] R. Ramadan and Y. Widyani, "Game development life cycle guidelines," in 2013 International Conference on Advanced Computer Science and Information Systems (ICACSIS), 2013, pp. 95-100. 